\title{
Multiband Reconfigurable Antenna for Military Applications
}

\author{
Anil Kumar Patnaik \\ Department of ECE \\ Raghu Institute of Technology \\ Visakhapatnam India
}

\author{
K Abhi Sarika \\ Department of ECE \\ Raghu Institute of Technology \\ Visakhapatnam India
}

\author{
M Sairam Patrudu \\ Department of ECE \\ Raghu Institute of Technology \\ Visakhapatnam India
}

\author{
P Hema Meghana \\ Department of ECE \\ Raghu Institute of Technology \\ Visakhapatnam India
}

\author{
A Suresh \\ Department of ECE \\ Raghu Institute of Technology \\ Visakhapatnam India
}

\begin{abstract}
Based on compact coplanar waveguide fed frequency reconfigurable flexible antenna is presented. The design rules were proposed to use the flexible rogers RT/duroid 5880 as a material called substrate with small size of $30 * 28.4 \mathrm{~mm} 2$. The current distribution is modified by 2 switches on antenna board. The resonance frequency is modified under different switch conditions, making it a frequency antenna that can be reconfigured. CST MWS simulates antenna configuration. This proposed work of antenna that contains VSWR $<2$ and significant radiation patterns with actual gain over appropriate frequency bands. The design helps in achieving Radio Location in civil [4.7GHZ], Amateur Satellite[4.628GHZ], PMSE application[7.735GHZ], Radio location[3.962GHZ] in military
\end{abstract}

Keywords- Reconfigurable Antennas, CST MWS, Switches.

\section{I.INTRODUCTION}

Now-a-days people are habituated to use a single device for multiple applications .example a digital watch, mobile phone etc.., like we designed an antenna where a single antenna can be used for multiple applications, so here based on the frequency at which it radiates its application is defined. Here we are taking the reconfigurable antenna for designing and CST MWS software as medium of designing.

An antenna is a series of conductors (elements) that are attached electrically to the receiver or transmitter. Antennas may be equipped to send and receive radio waves similarly (both directional) and preferentially in a common direction (headway, high-gain, or "flash" antennas) in all horizontal directions. An antenna may include noncomponents, parabolic reflectors, bell, or parasite elements to direct the radio waves in a beam or other preferred pattern of radiation.

A patch antenna is a low-profile radio antenna installed on a flat surface. There is a small, rectangular sheet of metal "floor," placed on a bigger sheet of metal called the earth layer.

A reconfigurable antenna is an antenna which can adjust its radiation and frequency features dynamically, controllably and reversibly. Reconfigurable antennas incorporate an internal mechanism to purposefully re disseminate the radio stream through antenna to provide a dynamic response. Configurable antennas differ from smart antennas, because instead of an external stratification network the reconfiguration mechanism is contained within the antenna. Instead of an external beamforming network lies the process inside an antenna. The reconfigurable antennas optimize the antenna capacity in a changing environment or full fill emerging operational requirements

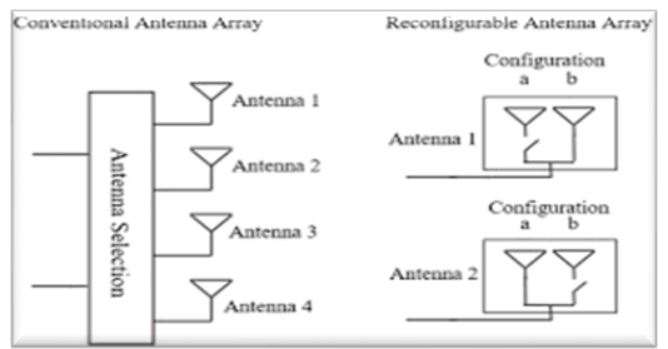

Figure a. conventional Antenna and Reconfigurable Antenna

In order to ensure good gains, reliable radiation patterns and good impedance in all operating conditions, the reconfigurable antenna designs must concentrate on the following points:

which antenna characteristics (e.g. wavelength, radiance pattern or polarization) are to be changed and which technique can minimize negative effects in order to reconfigure the antenna output

A reconfigurable antenna provides the same features as numerous antennas. This saves on expenses, weight, quantity and energy for maintenance and repair. The following paragraphs describe the essential antenna layout parameters.

Multi-band antennas can operate well over different frequency bands with a predictable radiation pattern. Nevertheless, in addition to the target frequency, multiband antennas continuously emit electromagnetic waves at all allowed frequencies. Yes, ambient electromagnetic radiation is detrimental to the well-being of humans. 


\section{LITERATURE STUDY}

The proposed design generally helps in multiband applications. The wide spread of new wireless technology and consumer demands for multiple services on a single device gained a lot of exposure from an antenna running on several frequency strips [1]. A frequency band is usually linked to a specific wireless service, which implies a multi-band antenna is needed in a single wireless device to support multiple networks [2]. It can run several band antennas with a strong gain and stable radiation pattern on different frequency bands. In addition to the target level, however, multiband antennas concurrently relay electromagnetic waves to all approved frequencies. In fact, the cellular equipment requires electromagnetic radiation [10].

Frequency endurance can be accomplished by various switch sort, such as varactor diodes [3], pin diodes[2], RF MEMS[5] and FET [6]. Varactor diodes [1] in are used to reconfigure varactor diodes, but varactor diodes are nonlinear and have small continuous tuning range [4]. Switching between several bands calls for a large number of pin diodes which increase insertion loss and render the distortion circuit complicating [7]. RF MEMS has a small loss, but is costly to deploy [8]. Three pin diodes for LTE, AMT fixed services and WLAN applications are used in U-shaped and L-shaped slots [9].

It recommends an airborne radio frequency antenna, AMT Set, WLAN, unlicensed WiMAX and X-band systems, which can be reconfigured at any time [11]. By using switches that provide broad tuning of the operating bands, the productive electrical duration of the antenna is modified. The findings calculated and assessed are well known. The antenna fits well on the target bands and has strong radiation patterns. Simplicity, compactness, configurability and versatility render it a popular wireless technology choice [12].

\section{PROPOSED METHODOLODY}

The whole process of designing is done in CST MWS. Here the antenna designing is done first on which the switches are altered accordingly

\section{A. SWITCH S1 AND S2 OFF}

Here coming to the process of designing. Now the two switches are involved in current transfer. The two switches s1 and s2 play a major role here these switches are placed at inner and outer radiator respectively. The CPW feeding line is attached to the central heater with a diameter of $1 \mathrm{~mm}$. For Switch S1 and S2 the interior and exterior heaters are connected with the central heaters. First of all, it is designed to feed CPW rectangular antenna with a single $4.8 \mathrm{GHz}$ channel. Within and around the central radiator, the triangle is added to achieve additional reflection frequencies whose results are shown at figure [1]. Now extending the implementations with switches operations is shown from here. With these implementations the antenna and their results are shown below

\section{Both switches are s1 and s2 are put OFF:}

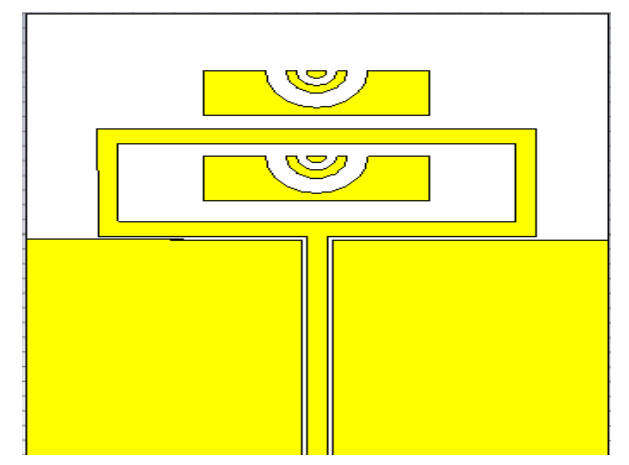

Figure 1. Reconfigurable antenna when S1 and S2 is OFF

so after the simulation of above design we get the following result.

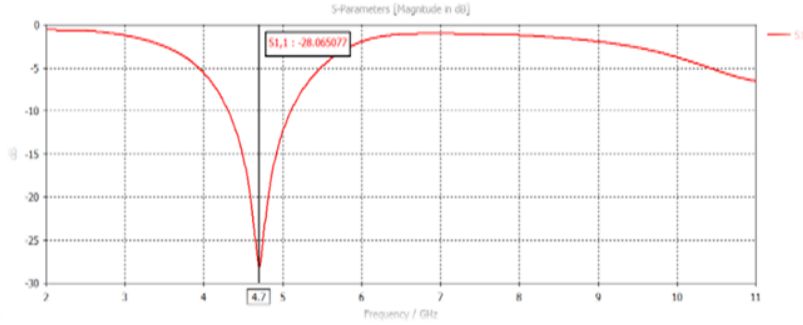

Fig.1(a) S-Parameter when Switches $S 1$ and S2 are OFF

The antenna simulates at $4.7 \mathrm{GHZ}$ which has aeronautical radio navigation application .so by varying the switches positions later the remaining applications can be notified where it proves that multiband applications on single antenna.

\section{B. SWITCH S1 ON AND S2 OFF}

Here switch s1 is kept on and switch s2 is kept off which is shown below

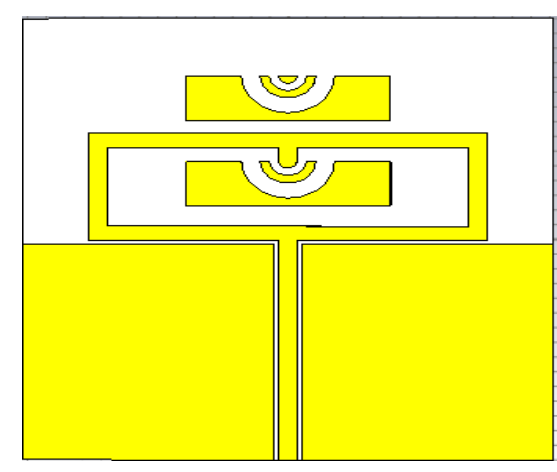

Figure 2. switch s1 on and switch s2 off

When switch $\mathrm{S} 1$ is on and switch $\mathrm{S} 2$ is off the current radiates in inner radiator and radiates at frequency of 4.628GHZ. 


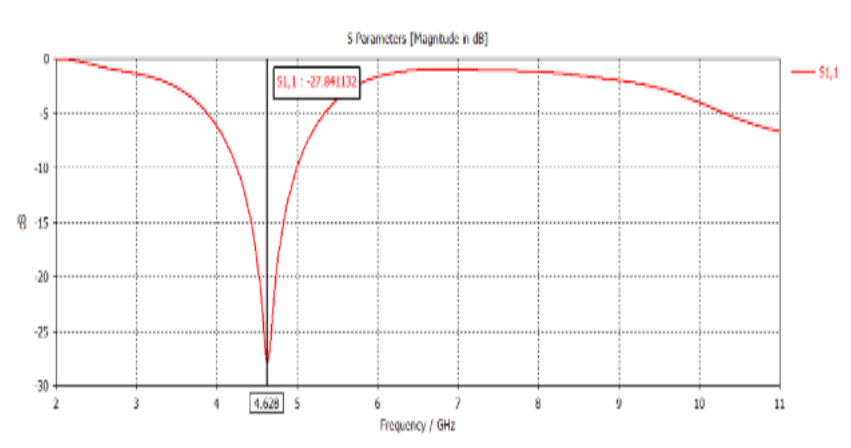

Figure 2(a) s-parameter when s1 switch ON and s2 switch S2 OFF

Here we observe that $\mathrm{s}$-parameter is shown as above. The radiation frequency at $4.484 \mathrm{GHZ}$ has RADIO DETERMINATION application

\section{SWITCH S1 OFF AND SWITCH S2 ON}

Now switch $\mathrm{s} 1$ is put OFF and switch s2 is put ON. So current circulates through $\mathrm{s} 2$ that is at the outer radiator respectively. This is clearly shown below

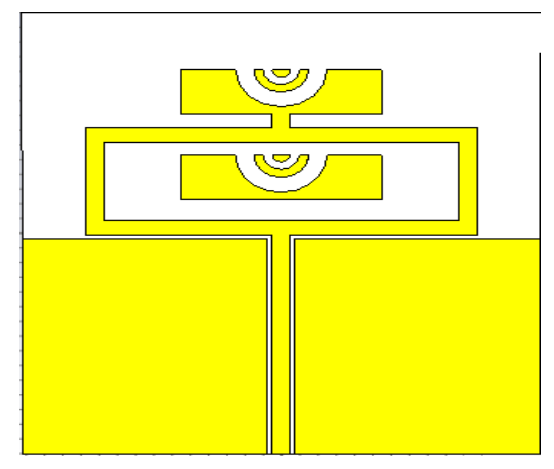

Figure 3. Switch S1 OFF Switch s2 ON

The antenna radiates at $3.962 \mathrm{GHZ}$ and $\mathbf{7 . 7 5 9 G H Z}$ respectively. Here it radiates in multiband manner. The sparameter results are shown below

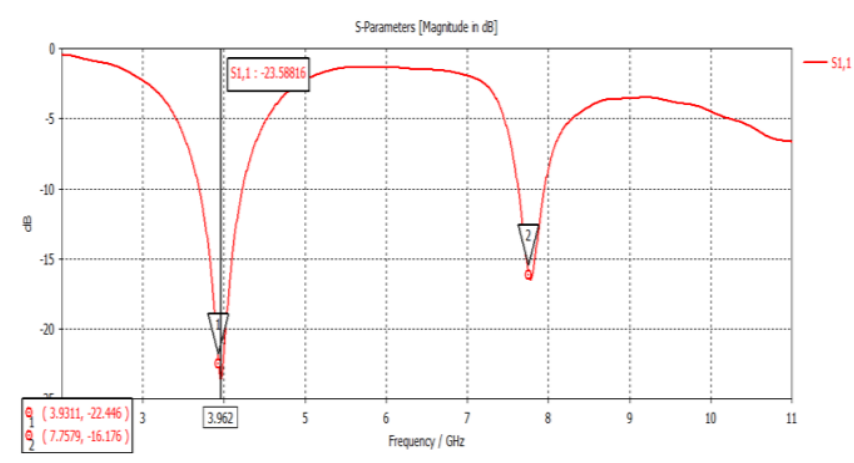

Figure 3(a) s-parameter when $S 1$ is $O F F$ and $S 2$ is $O N$

\section{Now with switches s1 ON and s2 ON}

Yes, now switches are fixed and put ON. Here when both the switches are kept $\mathrm{ON}$ the antenna radiates at certain frequency of $3.384 \mathrm{GHZ}$ respectively. Now the current circulates at main radiator only. This can be observed below

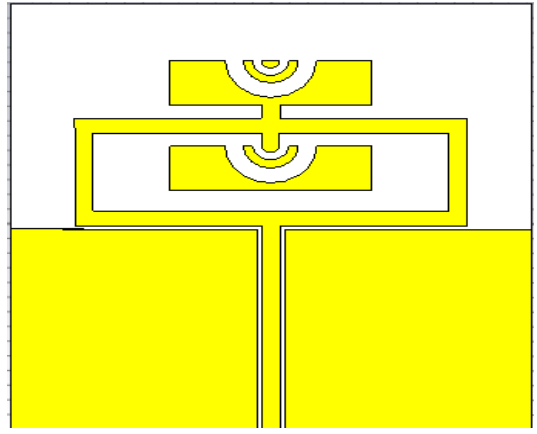

Figure 4. switch s1 ON and switch s2 ON

Now the antenna radiates at $7.7352 \mathrm{GHZ}$ and $\mathbf{3 . 9 3 1 1 G H Z}$ respectively. Here the parameter results show that antenna radiates in multiband manner that is at two points. The sparameter results are shown below

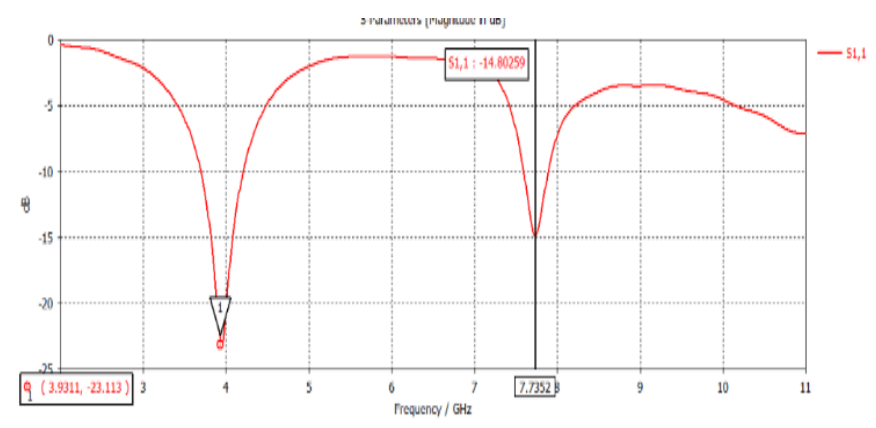

Figure 4(d) s-parameter result when $s 1$ is $O F F$ and $S 2$ is $O N$

\section{RESULTS}

From 3(a),3(b),3(c),3(d) observations say that antenna radiates at different frequencies based on switching positions in four different ways. The obtained results are tabulated below in overview

TABLE: OUTPUTS

\begin{tabular}{|c|c|c|}
\hline \multicolumn{2}{|c|}{ SWITCHES } & \multirow{2}{*}{ Frequency(GHZ) } \\
\hline S1 & S2 & 4.7 \\
\hline 0 & 0 & $3.962,7.759$ \\
\hline 1 & 0 & 4.628 \\
\hline 0 & 1 & $7.735,3.9311$ \\
\hline 1 & 1 & \\
\hline
\end{tabular}

\section{CONCLUSION}

The reconfigurable antenna design here is for purpose of multiple applications. The Lightweight Modular and Frequency Reconfigurable Antenna is built, developed and defined.

The same is replicated using a CST Studio software simulation tool. The four frequency bands were obtained in this antenna where it promises that antenna radiates at different frequencies with the applications such as Radio location[3.962GHZ] in military, Amateur 
Satellite[4.628GHZ], Radio Location in civil [4.7GHZ], PMSE application[7.735GHZ] in accurate manner.

\section{REFERENCE}

[1] SHAH, S. S. A., KHAN, M. F., ULLAH, S., et al. Design and measurement of planar monopole antenna for multi-band wireless applications. IETE Journal of Research, 2017, vol. 63, no. 2, p. 194 204. DOI: 10.1080/03772063.2016.1261049

[2] LI, T., ZHAI, H., WANG, X., et al. Frequency-reconfigurable bowtie antenna for Bluetooth, WiMAX, and WLAN applications. IEEE Antennas and Wireless Propagation Letters, 2015, vol. 14, p. 171174. DOI: 10.1109/LAWP.2014.2359199

[3] GE, L., LUK, K. M. Frequency-reconfigurable low-profile circular monopolar patch antenna. IEEE Transactions on Antennas and Propagation, 2014, vol. 62, no. 7, p. 3443-3449. DOI: 10.1109/TAP.2014.2318077

[4] LI, T., ZHAI, H., LI, L. Frequency-reconfigurable bow-tie antenna with a wide tuning range. IEEE Antennas and Wireless Propagation Letters, 2014, vol. 13, p. 1549-1552. DOI: 10.1109/LAWP.2014.2344676

[5] CETINER, B. A., CRUSATS, G. R., JOFRE, L., et al. RF MEMS integrated frequency reconfigurable annular slot antenna. IEEE Transactions on Antennas and Propagation, 2010, vol. 58, no. 3, p. 626-632. DOI: 10.1109/TAP.2009.2039300

[6] YANG, X. L., LIN,J.CHegG., et al. Frequency reconfigurable antenna for wireless communications using GaAs FET switch. IEEE Antennas and Wireless Propagation Letters, 2015, vol. 14, p. 807810. DOI: 10.1109/LAWP.2014.2380436

[7] BHELLAR, B., TAHIR, F. A. Frequency reconfigurable antenna for handheld wireless devices. IET Microwaves, Antennas \& Propagation, 2015, vol. 9, no. 13, p. 1412-1417. DOI: $10.1049 /$ ietmap.2015.0199

[8] CHEN, G., YANG, X. L., WANG, Y. Dual-band frequency reconfigurable folded slot antenna for wireless communications. IEEE Antennas and Wireless Propagation Letters, 2012, vol. 11, p. 1386-1389. DOI: 10.1109/LAWP.2012.2227293

[9] HAN, L., WANG, C., CHEN, X., et al. Compact frequency reconfigurable slot antenna for wireless applications. IEEE antennas and wireless propagation methods

[10] LI, P. K., SHAO, Z. H., WANG, Q., et al. Frequency- and pattern reconfigurable antenna for multi standard wireless applications. IEEE Antennas and Wireless Propagation Letters, 2015, vol. 14, p. 333 336. DOI: 10.1109/LAWP.2014.2359196

[11] ROW, J. S., LIN, T. Y. Frequency-reconfigurable coplanar patch antenna with conical radiation. IEEE Antennas and Wireless Propagation Letters, 2010, vol. 9, p. 1088-1091. DOI: 10.1109/LAWP.2010.2093118

[12] BORHANI, M., REZAEI, P., VALIZADE, A. Design of a reconfigurable miniaturized microstrip antenna for switchable multiband systems. IEEE Antennas and Wireless Propagation Letters, 2016, vol. 15, p. 822-825. DOI: 10.1109/LAWP.2015.2476363 